\title{
Making Standards Stick: A Theory of Coupled vs. Decoupled Compliance
}

Kurt Sandholtz

sandholtz@byu.edu

Follow this and additional works at: https://scholarsarchive.byu.edu/facpub

Part of the Business Administration, Management, and Operations Commons

\section{Original Publication Citation}

Sandholtz, Kurt W. 2012. "Making Standards Stick: A Theory of Coupled vs. Decoupled

Compliance." Organization Studies 33 (5-6):655-79.

\section{BYU ScholarsArchive Citation}

Sandholtz, Kurt, "Making Standards Stick: A Theory of Coupled vs. Decoupled Compliance" (2012). Faculty Publications. 2038.

https://scholarsarchive.byu.edu/facpub/2038

This Peer-Reviewed Article is brought to you for free and open access by BYU ScholarsArchive. It has been accepted for inclusion in Faculty Publications by an authorized administrator of BYU ScholarsArchive. For more information, please contact ellen_amatangelo@byu.edu. 
Making Standards Stick:

A theory coupled vs. decoupled compliance

Kurt W. Sandholtz

Brigham Young University

\begin{abstract}
This paper presents an inductive account of how two divisions of the same corporation sought to standardize their engineering work. Although both groups achieved ISO 9000 certification, each was guided by historical antecedents and internal processes that left different legacies: a culture of cynicism and chaotic work practices in one division vis-à-vis a system of standardized work practices that are voluntarily (and often enthusiastically) followed in the other. The contrasting cases shed light on what happens when an external standard is adopted by an organization, converted into a formal directive, and then confronted by the norms and practices of an existing occupational community. More generally, the paper articulates how three common modes of social regulation - standards, directives, and norms - are interconnected in the process of implementing a standard in an organization, and the conditions under which institutional exigencies are either decoupled from or tightly coupled to technical work.
\end{abstract}

Keywords standardization, decoupling, occupations, work, engineers

\title{
Note
}

I thank Daniel Armanios, Diane Bailey, Steve Barley, Beth Bechky, Charles Perrow, Woody Powell, Isaac Waisberg, and participants in the Stanford Networks and Organizations workshop for helpful feedback. Two anonymous reviewers and special issue editor Nils Brunsson offered suggestions that greatly improved the paper. This research was made possible by National Science Foundation grant ITR 0427173.

\section{Bio}

Kurt Sandholtz is an assistant professor in the Management department of Brigham Young University’s Marriott School of Business. His research investigates how occupations influence and are influenced by organizations and institutions. This paper was published while the author was a Ph.D. candidate at Stanford University’s Center for Work, Technology, and Organization. Email: sandholtz@byu.edu. 


\section{INTRODUCTION}

Between 1997 and 2002, a pair of engineering divisions of the same large manufacturer decided to seek ISO 9000 certification. Both were successful. Like many of their competitors and suppliers, they conformed - albeit belatedly - to the international standard for quality processes.

The achievement of these two engineering divisions would appear a rather unremarkable story of institutional isomorphism (Beck and Walgenbach 2005). The familiar elements are all present: The influential International Organization for Standardization in Geneva creates a standard (ISO 9000) that evolves from its technical roots to become a largely symbolic seal of approval (Walgenbach 2007). As ISO certification takes on characteristics of 'soft law' (Djelic and Sahlin-Andersson 2006), a late-adopting organization seeks the designation not for technical reasons, nor because of regulatory pressure, but simply to gain legitimacy (Westphal et al. 1997; Zbaracki 1998). Once achieved, compliance with the standard becomes largely ceremonial and, hence, decoupled from the technical work of the organization (Meyer and Rowan 1977; Fiss and Zajac 2006).

The problem with this story is that it is only half true. One of the engineering groups indeed followed this stylized sequence of events, but the other division pursued a path that departed dramatically from the institutional trajectory. Although both groups achieved ISO 9000 certification, their efforts were guided by historical antecedents and internal processes that left contrasting legacies: a culture of cynicism and chaotic work practices in one division vis-à-vis a system of standardized work practices that are almost universally (and often enthusiastically) followed in the other.

What factors led two divisions of the same company to achieve such divergent outcomes - one decoupled, one tightly coupled - in pursuit of standardization? Existing scholarship 
provides only partial answers to this question. At a broad conceptual level, the persistence of heterogeneity in the face of homogenizing tendencies is well theorized in a variety of literatures (Czarniawska and Sevón 1996; Feldman and Pentland 2003; Bromley et al. 2011). Theoretical treatments of standardization advance similar arguments, pointing out that standards are abstractions and, hence, require adaptation to local idiosyncrasies (Furusten 2000; Seidl 2007; Timmermans and Epstein 2010). Thévenot (2009: 810) goes as far as to suggest that the ostensible goal of standardization - uniformity across time and space - is an 'impossible accomplishment in the face of actual practice.' The empirical evidence largely supports Thévenot's assertion. Decoupling is perhaps the most replicated finding across studies of standardization. These studies have shown that core work processes remain relatively unperturbed by ceremonial certification efforts (Zbaracki 1998; Walgenbach 2001; Beck and Walgenbach 2005; Boiral 2003, 2007; Storz 2007). Yet despite theories that predict it and evidence that confirms it, decoupling remains an undertheorized component of neo-institutional thought (Boxenbaum and Jonsson 2008), and tight coupling between the substantive and the symbolic is an anomaly that demands explanation.

This paper addresses both decoupling and tight coupling, in the context of two contrasting standardization initiatives. In one case, a decoupled ISO 9000 drive generated staunch resistance among the engineers. In the other case, the engineers at first accommodated a similarly decoupled ISO 9000 effort, then later created their own version of standardized engineering that exceeded ISO requirements. Inductive analysis of the two cases yields a general model of how three common types of rules - standards, directives, and norms (Brunsson and Jacobsson 2000a) - are interconnected when an organization adopts and implements a standard. 
The paper is organized as follows. First, I review the literatures on standardization and decoupling. Next, I describe the research setting and methods. Third, I reconstruct the implementation of ISO 9000 in the two engineering groups and chronicle how the standards were transcended in one of the groups. Finally, I present a general model of standardization that summarizes the conditions that lead to coupled or decoupled compliance. I discuss the implications of this model for reinterpreting prior empirical findings, and conclude by identifying future lines of inquiry.

\section{THEORETICAL FOUNDATIONS}

Standards are mechanisms of social order. They are a hybrid form of control, incorporating properties of both formal directives and informal norms (Brunsson and Jacobsson 2000a). Like directives, standards are explicit; yet like norms, compliance to standards is voluntary. Unlike norms, standards do not originate in repeated patterns of social interaction, yet their originators typically have no formal power of enforcement (unlike those who issue directives). Standards, then, are characterized by formal authorship yet voluntary adoption (see Table 1). Both of these aspects - authorship and volition - catalyze the dynamics explored in this paper, and thus deserve to be unpacked.

[ Table 1 here ]

\section{Who sets the standard?}

The rise of global standards developing organizations (SDOs) has coincided with the rationalization of modern society (Mattli and Büthe 2003; Timmermans and Epstein 2010). Scholars generally agree that SDOs codify and disseminate expertise in the form of rules (Jacobsson 2000), and that scientific and technical experts have therefore 'become central and prestigious participants in world society’ (Meyer et al. 1997: 165). Studies of the internal 
workings of the largest SDO - the International Organization for Standardization (ISO) - reveal a complex technocracy, made up of some 260 Technical Committees, each with its subcommittees and working groups (Tamm Hallström 2004).

Social studies of science emphasize that the establishment of ostensibly neutral rules can be a highly contested and contingent process. No one disputes the influence of technical professionals and other epistemic communities in the production of standards (Scott 2008), although research has largely ignored the role of these communities as consumers and implementers of standards. Instead, analyses of standardization can be grouped into three broad categories according to how they conceptualize the actor who is the target of the standard. The first category includes studies of transnational governance, in which the players are nation-states, multi-national corporations, and other members of global institutional fields (Mattli and Büthe 2003; Djelic and Sahlin-Andersson 2006; Ahrne et al. 2007; Djelic and Quack 2008). In this tradition, standards help to 'organize organizations,' and adoption hinges, ultimately, on the sociopolitical legitimacy conferred by the standard. The second category includes studies of the implementation of standards at the organizational level (Walgenbach 2001; Beck and Walgenbach 2005; Boiral 2003, 2007; Storz 2007). Such studies have repeatedly found that mechanisms of compliance are decoupled from technical work processes. The third category includes studies of how unique individuals encounter an increasingly standardized world (Lampland and Star 2009; Higgins and Larner 2010). None of these sets of studies pays attention to professional communities as recipients (rather than originators) of standards.

The omission is consequential. To knowledge workers, it matters greatly whose expertise is distilled in the standard. Indeed, standards are likely to be resisted by individuals who consider themselves 'highly autonomous, innovative, and different' (Brunsson and Jacobsson 
2000b:134), a description that fits the members of many professional communities. Professionals seek control over their own knowledge base and the types of problems to which it is applied: Abbott (1998: 3) asserts that 'jurisdiction is the defining relation in professional life,' and Scott and Meyer (1991: 130) note that 'as individual practitioners, professionals jealously guard their discretion over instrumental decisions.' Yet, existing empirical work has made little use of the professional lens, despite recognition that standards are invariably introduced into settings 'already populated by practices, tools, people, and other standards' (Timmermans and Epstein 2010: 79). The present study seeks to understand what happens when professionals confront abstract standards produced in isolation by distant experts.

\section{Voluntary for whom?}

Timmermans and Epstein (2010: 81) observed that 'the trick in standardization appears to be to find a balance between flexibility and rigidity and to trust users with the right amount of agency to keep a standard sufficiently uniform for the task at hand.' Unintentionally, this statement violates a basic tenet of Brunsson and Jacobsson's definition: To argue that users are entrusted with varying amounts of agency suggests that following the standard is not entirely voluntary. Likewise, scholars of transnational governance often refer to international standards as 'soft law,' where 'soft' emphasizes the voluntary aspect of standards, while 'law' implies that non-compliance carries consequences.

These verbal anomalies stem from a second paradoxical aspect of standards: their seeming inseparability from traditional hierarchical control. According to Brunsson and Jacobsson (2000a:13), 'a standard in society at large becomes a directive for the members of an organization whose management has decided that the organization is to follow the standard.' In other words, senior managers exercise agency in adopting a standard; the rank and file exercise 
obedience. In their analysis of anti money-laundering regulation, Hülsse and Kerwer (2007) note this contradiction between hierarchy and standardization. The authors suggest that heavy-handed enforcement of directives undermines the legitimacy of the standard itself. Legitimate or not, managers’ ability to enforce compliance is limited in any case, especially among professionals, whose ethos is highly resistant to command (Abernethy and Stoelwinder 1995; Brunsson and Sahlin-Andersson 2000). Symbolic compliance - decoupled from the exercise of technical judgment- is one way for the individual to assert his or her professional autonomy. Thus, this paper seeks to explicate how the conversion of external standards into organizational directives sows the seeds of decoupling.

\section{Toward a more nuanced view of decoupling}

Organizations often make a symbolic show of conforming to institutional pressures, at the same time buffering their technical processes from disruption (Meyer and Rowan 1977; Oliver 1991; MacLean and Behnam 2010; Pache and Santos 2010). Accordingly, studies of ISO 9000 and other quality management systems show rampant decoupling of compliance-driven work (Zbaracki 1998; Walgenbach 2001; Vallas 2003; Storz 2007). Yet, the literature on decoupling suffers from three limitations that are relevant to the present study. First, decoupling has been theorized in binary terms; it is either present of absent (Westphal and Zajac 2001; Fiss and Zajac 2004; Stevens et al. 2005). This analytical convenience glosses over important qualitative differences in processes of decoupling. The present study finds compelling evidence for two different types of decoupling: a malignant variant that resulted from strong occupational opposition to an imposed standard, and a benign variant that reflected a consensual implementation of a standard. 
Second, the decoupling literature has not paid enough attention to 'the unintended effects of decoupling, such as whether it affects morale and fosters cynicism within the organization' (Boxenbaum and Jonsson 2008: 91). Empirical evidence is beginning to correct this deficiency. For example, the effects of decoupling on morale figure prominently in Boiral's (2003) crosssectional study of 47 managers and workers at companies that had achieved ISO certification. Deep cynicism was expressed by $21 \%$ of the respondents; $43 \%$ were supportive and positive toward the ISO certification even though they openly acknowledged that it was decoupled from technical work; the remaining 36\% - more than half of whom were internal quality consultants saw no evidence of decoupling and were characterized as 'quality enthusiasts.'

MacLean and Behnam (2010) take a further step, questioning the sustainability of decoupled practices. Their analysis of a large insurance company illustrates how shady sales practices persisted despite a formal organizational process designed to prevent them. The account suggests that decoupled self-monitoring systems are riddled with conflicts of interest that eventually compromise the organizational legitimacy such systems were intended to protect.

In the cases presented in this paper, decoupling was motivated by occupational rather than financial interests, although the impotence of decoupled self monitoring is clearly seen in one of the cases. In the other case, a robust system of self-monitoring evolved into a feedback loop ensuring that a homegrown system of standards remained tightly coupled to actual practice.

Understanding the phenomenon of tight coupling presents a third area of opportunity in the decoupling literature. In fairness, the neo-institutional paradigm originated as an alternative to contingency theory and its assumption of tight coupling between external demands and internal structures (Scott and Davis 2007). Over time, however, decoupling has achieved such presumptive status that scholars have coined a new term - recoupling - to describe cases in 
which organizations attempt to overcome decoupling’s destructive consequences (Espeland 1998; Hallett 2010). The study of tight coupling is thus a vital counterfactual within neoinstitutional theory. To this end, Sauder and Espeland (2009) analyze the tight coupling between the behavior of law school administrators and the external demands of the law-school rankings system. Like compliance with a standard, participation in the law school rankings process is optional. Yet because the rankings are simultaneously coercive and seductive, Sauder and Espeland show that administrators’ initial resistance evolved into grudging compliance and then internalization of the rankings game. The account presented here contributes a different insight to theories of tight coupling, suggesting that when internalization precedes standardization, tight coupling is a fait accompli.

In summary, the primary theoretical aim of this paper is to expand our understanding of the dynamics of standardization, focusing on the connections between standards, directives, and norms. By examining in depth how an organization implemented a common external standard in two of its divisions, the paper highlights a previously opaque but nontrivial factor that influences the path of standardization: the occupational norms and practices of those expected to standardize their work. This focus on the implications of standardization at the level of concrete work practices contributes to our understanding of decoupling: Under what intra-organizational conditions do individual work practices become decoupled from extra-organizational symbolic action? Conversely, what conditions are associated with individual practices that remain tightly coupled to the imposed requirements of external legitimacy?

\section{RESEARCH SETTING AND METHODS}

To gain insight into the dynamics of standardization, I studied a corporation in the process of migrating standards from its manufacturing plants to its engineering and design 
centers. Amalgamated Industrial Manufacturing, or AIM (a pseudonym) is a century-old global manufacturing company headquartered in the eastern United States. AIM designs, manufactures, and sells a range of consumer durable goods, employing more than 200,000 people worldwide. Guided by principles of theoretical sampling (Eisenhardt 1989), I identified two engineering groups that were in the midst of on-going efforts to standardize engineering work, and were subject to a regimented product development process imposed by the corporation. The composition of both groups was nearly identical in terms of educational background, career history, and demographic makeup. This approach made it possible to assess the differences in standardization processes that led to divergent outcomes between the two groups (Barley 1986; Vallas 2003).

Both groups' standardization efforts included adoption of ISO 9000, the most widely adopted management standard in the world. In 1987, the International Organization for Standards (ISO) first published guidelines defining the fundamental elements of a production system that would result in high-quality products. Since then, the standards have evolved to become general management guidelines for the consistency and reliability of any organizational process (Tamm Hallström 2000).

Although both groups achieved ISO 9000 certification, their approaches to standardization diverged on a number of theoretically relevant dimensions. Engineering Group 1 (EG-1) was tasked with designing the structural frame within which all subsystems and components were integrated. Engineering Group 2 (EG-2) was responsible for the design of a mechanically complex subsystem for AIM's key product line. The two groups did not interface directly with one another. EG-1 had 936 employees and EG-2 had 628. The nature of the day-today engineering work in both groups was similar: mechanical engineers used computer-aided 
engineering software to visually and mathematically define components and structural subassemblies in three-dimensional space. Their work output was the mathematical specification of parts ready for manufacture by third-party suppliers or by their own manufacturing plants.

To understand the implementation of standard work in the two groups, I relied on three data sources: archives, semi-structured interviews, and participant observation. I collected data from April 2008 to September 2008. During the months of July and August, I was on-site five days per week. The company provided unrestricted access to their proprietary intranet sites and on-line document storage system, allowing me to collect more than 800 pages of documents for analysis, including presentations (the favored medium of internal communication at AIM), training manuals, screen shots from intranet sites, and copies of emails.

Informants were identified using a combination of purposive and snowball sampling. My guiding objective was to talk to people at all levels of the hierarchy in both groups, who also represented the full range of design tasks for which the groups were responsible. I took care to identify individuals who held differing views of the value of standardization. Interviews with 43 members of EG-2 and 20 members of EG-1 lasted for 60 minutes on average; all were recorded and transcribed, producing 850 double-spaced pages of text (see Table 2). The interviews constituted the primary data source, but were supplemented by observing engineers at various times of day.

\section{[ Table 2 here ]}

Combining these data sources, I constructed a chronological narrative that captured each group's experience with standardization. To mitigate retrospective bias, I triangulated interview data with archival evidence, such as company training manuals, documents posted on the company intranet, or presentations provided by informants (Miles and Huberman 1984). When 
my subsequent analysis revealed gaps in the data, I followed up with informants to obtain the missing information. Detailed reconstructions of events were reviewed by a cross-section of engineers, managers, and executives within each group, and corrected accordingly. In the end, these panels of informants attested to the accuracy of the case summaries.

With these summaries in place, I began a three-phase process of analysis, following established guidelines for developing grounded theory (Strauss and Corbin 1990; Eisenhardt and Graebner 2007). The first phase required a return to the raw data, using open coding to identify concepts relevant to each case summary’s overall narrative. During a second analytical phase, axial coding around the concept of decoupled (or coupled) implementation within EG-1 (or EG2) yielded a highly salient dimension related to engineers' occupational norms. In the third phase of analysis, I compared across the case summaries, iterating between my data and the literature on standardization and decoupling. I gradually rearranged the case histories not just chronologically, but by levels of analysis, noting similarities and differences in the two histories as the external standard crossed the boundary between the institutional field and the organization, was converted into a directive within the organization, and ultimately was either considered counter to or consonant with the norms and practices in the two groups. Satisfied that this view of the data best satisfied the criteria of empirical fidelity, analytical purchase, and theoretical import, I organized all data according to this perspective and produced the abbreviated accounts presented in the section that follows.

\section{FINDINGS}

\section{Engineering Group 1: From standard to directive to decoupling}

EG-1's experience with ISO 9000 is consistent with findings from previous research: certification-related activities were decoupled from day-to-day technical work (Boiral 2003; 
Walgenbach 2007). However, my findings shed light on areas overlooked in prior studies: the processes of adoption, implementation, and decoupling, with particular attention to engineers' rationales for rejecting standardized practices.

The pre-adoption context. EG-1had its roots in an acquisition made early in AIM's history (mid-1920s). Formerly a supplier, the acquired company became a central corporate division responsible for all structural engineering. Because AIM had purchased the specialist company to prevent competitors from accessing its expertise, the company was not allowed to provide its services to external customers. In addition, EG-1's role in the production process was highly integrative: its structural frames had to interface with at least six other design and engineering groups, creating a complex system of interdependencies.

Following a wave of decentralization in the 1940s, all engineering activities were distributed to AIM's semi-autonomous product divisions. Over time, divisional engineering groups developed their own standard processes and work routines. In the 1980s, AIM began again to centralize its structural engineering work. A series of reorganizations culminated in 2004 with the consolidation of all structural engineering in the corporate research center. EG-1 thus inherited work standards from a number of different internal sources, resulting in a 'tribal' knowledge base, as one informant put it.

EG-1's history, then, suggests two factors that impinged on its implementation of ISO 9000. First, the group had no direct contact with AIM's external customers. Second, the recent reintegration of disparate structural engineering groups into a corporate center of expertise meant that the engineers' preferred work practices and analytical approaches were divisional inheritances that were far from standardized. 
Adopting an external quality standard. Attempts to unify engineering processes around a common standard had begun in 1994, prior to corporate centralization. Senior managers in EG-1 launched a series of workshops with the goal of 'synchronizing' the multitude of engineering processes within the organization. There followed a sequence of short-lived quality initiatives, each involving slightly different rhetoric and exerting little impact on engineering processes (see Table 3). This cycle of starts, stops, and restarts had lasting effect on engineers' attitudes. One EG-1 engineer said that 'for an AIM person to be cynical about a new process tool is a normal state' (Informant 53). Another, from a different part of the EG-1 organization, pointed out that:

We're famous for programs of the day. ... You just kind of go through it, you take whatever training they want you to because they tell you to, and you do what you need to, but it does nothing for your job. Zero. Zilch. As a matter of fact, it just eats up more time. (Informant 49)

\section{[ Table 3 here ]}

Among my informants, the most salient of these false starts was the executive-led initiative, launched in 2000, to achieve ISO 9000 certification. The motivations to adopt the standard were threefold: First, a key competitor announced it had recently achieved certification for its entire U.S. engineering function. Lacking any evidence that such certification would provide tangible economic benefits, AIM executives nonetheless felt pressure to 'keep up.' Second, AIM's manufacturing plants had been ISO certified within the past two years and the labor union was beginning to push for 'equal treatment' of headquarters staff organizations. Third, EG-1's work was suffering chronic quality problems. In a highly complex, interdependent system, identifying and correcting root causes posed a significant technical challenge. An explanatory email from an internal quality expert who was directly involved in the ISO 9000 initiative is illuminating: 
It was rumored that [EG-1] might be 'drunk and disorderly' around the notion of a quality system; executives would make off-the-cuff remarks to that point. There was a belief that [ISO] registering the product development activity of [AIM] would help to bring efficiencies to the organization and help eliminate waste. The other product engineering centers around the globe all had ISO registrations. North America was the exception. Having North America achieve an ISO registration would be good for global relations. (Informant 1c)

These multifaceted motivations shared a common characteristic: the absence of a marketdriven imperative for adopting the ISO standard. Instead, the motivations were a mixture of mimesis (copying both an external competitor and other AIM engineering centers), internal politics (appeasing the union), and the ‘cropping up’ model of organizational reform (i.e., trying the next new thing; see Brunsson and Olsen 1993). In sum, pursuit of ISO certification represented a readily available, externally legitimate and internally conciliatory gesture, the successful execution of which offered some hope of substantive impact. Perhaps more tellingly, the adoption of the ISO standard was a management decision, not a grass-roots movement among engineers.

Implementation: from external standard to decoupled directive. Once AIM decided to achieve ISO certification, the standard was transformed into a directive. Managers took the lead in communicating the purpose of the ISO drive to their employees, but the certification effort itself was delegated to an internal staff organization. Significantly, this staff group was located in a distant part of the building, on a separate floor from the product design engineers. These staff specialists were tasked with gathering documentation and preparing detailed 'work instructions' - generalized descriptions of how each engineering job contributed to overall quality. An internal quality staffer who participated in the ISO certification effort noted,

Every individual had to have work instructions. Because if they didn’t, we couldn't audit them - we couldn't be [ISO] registered. Some of it was driven by this fear of audit. My God, we don't want an auditor wandering up to somebody and saying, 'What are you doing?' and they go, 'I don’t know.'. . . We kind of went overboard when we used this 
phrase 'work instructions,' and we wrote thousands of them, thousands, down to the minutia level. (Informant 1a)

Engineers were expected to memorize their work instructions so that they could recite them for ISO auditors, with punishment for poor performance. Consider the following recollection from an EG-1 informant:

We went through a very expensive, non-value-added ISO process here, where we had to memorize what we did in our jobs, and when the ISO man came around, we had to regurgitate what we memorized and if we screwed it up, we were flogged by the highest portions of management: 'How could you fail the ISO? You failed ISO!' (Informant 51)

Despite being disconnected from its technical work, AIM’s ISO preparations paid off with successful certification in 2002. The ISO audit process was capable of being 'gamed' (Walgenbach 2001; Boiral 2003).

Abandoning the standard. ISO registration requires recertification every three years. In 2004, prior to EG-1's first recertification audit, the executive over EG-1 announced that the organization would no longer seek ISO approval. Instead, EG-1 engineers were urged to continue to apply the standards of their own accord. An excerpt from the executive’s formal announcement is reproduced below:

... a recent decision has been made that will allow Headquarters' ISO 9000 registration to lapse by March 2005. . . . The primary rationale behind this decision is that the main benefit of ISO 9000 registration is the internal benefit, which we believe can be sustained without external, third-party audits. ... Our employees have been thoroughly trained and are proficient at performing their assigned responsibilities. We are certain that this expertise will be used to make further improvements to excellent standard work practices that are already in place. In addition, much of the infrastructure that was in place to support ISO 9000 will be maintained to ensure that standardized work implementation continues to thrive within the Headquarters organization. This transition should yield few, if any, substantive changes to the way we perform our daily responsibilities.

Five of the nine engineers I interviews expressed the view that that the claimed 'internal benefit' of the ISO process was non-existent and that the remaining ISO 'infrastructure' - a fully-staffed 
internal consulting organization that produced quarterly updates to work instructions - continued to be out of touch.

Irrelevant work instructions may have been symptomatic of decoupling, but they were not its cause. When asked what derailed continued use of the standards developed for the ISO 9000 certification drive, 16 of the 20 EG-1 informants indicated that standardized approaches were antithetical to the work of design engineers. There were two principal variations on this theme. Twelve informants framed standardization either as the opposite of creativity or a threat to their autonomy, or both. These informants used pejorative labels such as 'cookbook engineering’ (or following a 'recipe’), ‘catalog engineering,' or becoming 'knowledge robots.'

The following statements are illustrative:

I've never, in years, heard my manager say, 'Have you referred to the standardized work for this issue?' It never comes up. It's just like, 'Let's get the job done. You're an engineer, you know what you need to do.'. . . And there is probably some feeling that standardized work equals cookbook engineering, which equals 'don’t use your brain.' (Informant 44)

Engineering in my mind cannot be that automated and that rigid. Sure enough, it needs to be guided by certain absolutes and by certain rules, but then there's a creative element of it that really makes engineering fun. And engineers tend to want to have that freedom. They tend to not want to be constrained. They tend to not want to be treated as, you know, virtually sort of knowledge robots that crank out solutions with very rigid sets of formulas. (Informant 55)

Another subgroup of engineers (4 informants) objected to standardized work on more practical grounds, insisting that their work was unpredictable and therefore defied routinization. They were always in 'fire-fighting mode.’ The following comments are representative:

I look at standard work . . . as a standard set of procedures that management has laid out for us that they would like us to follow on how to do a given task. Now all these tasks do not necessarily have an order to them. There is no set of standard work orders that encompasses everything that we do. A lot of what we do is trial and error, talking to your peers, figuring it out, finding a way to do it. (Informant 45) 
Standardization doesn't work - every program is different. ... At the high level, you can come up with some sort of a standard flow, standard deliverables. But when you get down to the nuts and bolts of it, that's where it's always going to be a little different. (Informant 49)

The most common reasons given for resisting standardization, then, were related to occupational self-image and the nature of engineering work. The historical context is noteworthy. A sequence of external quality standards had been brought into EG-1, only to be abandoned and replaced by the next 'new' thing. ISO 9000 was then introduced and compliance was mandated. Implementation, however, was carried out by a staff function that was administratively, spatially, and professionally decoupled from the design engineers. As a result, the ISO legacy - a voluminous catalog of work instructions - is essentially ignored by practicing engineers.

\section{Engineering Group 2: From standard to directive to norm}

In contrast to EG-1, EG-2 achieved ISO certification in 1997 and remains certified.Yet among EG-2 engineers, the ISO requirements simply were not salient, having been superseded by a rigorous, internally-developed work protocol known by the acronym POE (for 'Process of Engineering'). EG-2's engineers executed their technical work in a way that was consistent with ISO requirements without reference to the standard- the epitome of tight coupling. Indeed, in 43 interviews regarding their standardized work processes, EG-2 engineers mentioned ISO certification exactly twice. To illuminate the factors that contributed to the external standard being eclipsed by internal processes, I will briefly review EG-2’s history, its motivation for adopting the ISO standard, and the subsequent evolution of standardization within the group. The early sequence of events bears strong resemblance to the experience of EG-1; the ending of the story, however, is markedly different. 
The pre-adoption context. EG-2 designs a component that was pioneered by AIM in the 1930s and incorporated into AIM's products in the 1940s. The technology was highly innovative and gave AIM a significant advantage that it has never relinquished. Beginning in the 1950s, EG-2 began selling finished components and licensing the component's technology directly to other manufacturers. Also during this time period, a fire at an AIM facility required that most of EG-2's staff move to a new engineering center attached to a manufacturing plant. In the early 1980s, all of EG-2's engineers and technicians were moved to this location, a site 60 miles from headquarters. The EG-2 workforce had developed strong cohesion over 20 years of working under the same roof.

Adopting an external quality standard. According to AIM documents, in 1994 EG-2's senior leadership announced to its suppliers that they would need to be ISO certified by 1995. Many of EG-2's customers responded with a reciprocal request that EG-2 become ISO certified as well. Unless it wanted to forfeit this business, EG-2 had little choice but to adopt the standard. Thus EG-2's motivation for adoption was primarily commercial, in contrast to EG-1's mixture of institutional and political motivations. Furthermore, EG-2 pursued ISO registration from the outset, achieving certification in 1997. EG-1, on the other hand, had iterated through a sequence of seven different quality management approaches before deciding to pursue ISO registration in 2000 (see Table 3).

Implementation: from external standard to decoupled directive. Given such a business imperative, EG-2 responded with an ISO implementation plan that, unlike EG-1, did not require engineers to memorize generic work instructions. Instead, engineers were to describe their actual work, but use designated ISO terminology. Certification was achieved in 1997 without significant changes to existing work practices, although the burden of documentation increased. 
A seasoned engineer recalled the effort to document work practices in preparation for the ISO audit:

... trying to go to somebody's desk, file cabinet, or computer to prove that you meet their elements [i.e., ISO requirements] I think becomes more difficult and potentially could be very, very harmful because you wouldn't be able to show it, even though, okay, it's in the back of somebody's mind. If you're trying to demonstrate compliance, it would be awful tough. So, again, I think it became a side benefit and kind of a necessity to prove that we have the integrity that we think we do. (Informant 20)

Of note is the engineer's framing of ISO documentation as a 'side benefit' that ensured the 'integrity’ of the group’s engineering work. Along with its commercial motivation for adoption, EG-2's implementation of ISO standards engendered the type of accommodations expressed by Boiral’s ‘ceremonial integrators’ - individuals who see ISO 9000 as ‘a way of improving the organization’s image and obtaining new contracts’ (2003: 726). Put differently, EG-2’s implementation of ISO standards did not insult the engineers' professional dignity, in contrast to the punitive audit practices that had engendered cynicism among EG-1's engineers.

Thus, EG-2’s initial implementation of ISO 9000 was decoupled from core technical work practices but did not occasion the resentment registered by EG-1 engineers. EG-2 also departed from EG-1 in a more crucial way: the standard was not abandoned. Instead, the engineers themselves came up with a standardization protocol that not only satisfied ISO requirements, but did so in a way that was consistent with the engineers' occupational norms and tightly coupled with their work practices. (See Table 4 for a chronology of EG-2’s standardization initiatives.)

\section{[ Table 4 here ]}

Transcending the standard. In 2005, a subgroup of engineers in EG-2's new products group began to develop their own highly regimented engineering process. Prompted by inconsistencies between document formats and the difficulty of obtaining information on the 
latest design tolerances, simulation methods, and test evaluation criteria, the manager of the new products group told the subgroup of engineers that they could do 'little or no work on the [component] for the next two weeks':

We piled everybody into this room, and around-the-clock, around-the-shifts, we wrote out our process.(Informant 10a)

At the same time, a new executive was assigned to lead EG-2. He emphasized quality standards and, building on the subgroup's initial efforts, selected a team of the most respected engineers in the division and gave them the responsibility to extend the new product group's standardization effort across all of EG-2. In contrast to the structural isolation of the EG-1 quality staff, EG-2's standardization team reported directly to the executive; its team leader attended the executive's staff meetings and gave regular updates on progress. The product of this team's efforts turned into the 'Process of Engineering' (POE); it became EG-2's core quality management tool, superseding prior programs.

Many engineers in EG-2 were wary of the new process at first; 11 of the 43 EG-2 informants specifically mentioned their own and others' initial resistance. The following comments are typical:

Engineers don't like to be saddled with systems, so we were not the first ones in line to say: 'Okay, we'll use it.' (Informant 20)

Initially I thought a very regimented management process is not conducive to an inventive type of process.... And our work is - there's some invention in the sense that we are going to create a unique [component] almost every time. . . . But [POE] works very well. (Informant 39)

Unlike EG-2's ceremonial ISO compliance procedures, POE had been created by a group of EG2's most respected design engineers. The combination of 'bottom up' endorsement with 'top down' executive sponsorship proved potent enough to overcome engineers' reticence. 
POE's appeal derived primarily from what it was not: It did not tell engineers how to do their jobs. POE specified the inputs necessary for each task and identified criteria for judging the quality of the output. The actual engineering work was left to the professional discretion of the engineer. As described by its users, POE standardized everything but the creative engineering tasks, a fact which the data make evident: 39 of the 43 EG-2 informants asserted that POE did not limit their freedom to do creative engineering work. Only 2 informants intimated that POE hampered their creativity. (In contrast, recall that 12 of the 20 EG-1 informants indicated that standardized work was anti-creative.) The following comments reflect the majority view in EG-

2:

When you work with non-manufacturing organizations, especially engineering, the impression is that what they do is very creative and therefore it resists standardization. What we try to do is say: 'Okay, we'll give you that. What we will do is work on standardizing or making your job easier by taking the non-creative parts, which is generally administrative - document flow, information flow, how teams work together, how people interact - we'll take that portion that everybody agrees is non-creative but non-productive, we'll make that work better.' (Informant 19)

POE isn’t prescriptive. It doesn't tell you, 'Here’s how you fix a [specific] problem.' It just says, 'At this point you've got to have all of this stuff done.' Unfortunately, we haven't made all of the mistakes that we could possibly make yet, so we still invent some new ones and we've still got to figure out ways to fix those new ones. I think we're still rich with creativity and creative solutions. There's still enough of that to satisfy engineers. (Informant 6)

POE's web-based interface defines what completion looks like for some 270 steps in the design process; it also requires engineers to keep track of project milestones. Informants reported that they consult the website as often as five times a day, and no less than once every two weeks. Usage statistics are readily available for the POE website. The total monthly number of distinct users increased steadily over POE's first 30 months (see Figure 1), suggesting a wide acceptance of the system. The nomenclature associated with POE was noteworthy as well. The website 
avoided the terms 'standardization' and 'engineering factory,' and EG-2 informants never used the phrase 'cookbook engineering' in describing POE.

\section{[ Figure 1 here ]}

Finally, POE included internal audits, but they were used more for continuous

improvement than punishment. Often during audits, engineers would explain that their failure to follow POE standards was because of a superior technique that they had developed. An auditor described one such exchange, in which the standard documentation was not uploaded to the POE website as required:

[The engineer said,] 'Well, you know what, we used to use this form. But now, we use this - it's kind of expanded. So now, this [standard] really needs to be more in-depth and say this, this and this.' And we're like, 'You know, we'll do this, we'll copy and paste it and throw it in a Word document and ... we'll get it to [the change review board].' So, we also play the go-between. (Informant 26)

In effect, the auditors' 'go-between' role ensures that POE standards remain evergreen, constantly reflecting the engineers' improvements. The same sentiment was echoed by an engineer in describing the advantages of POE:

I think POE retains knowledge. Previously whenever you had to know what to do next, you had to go to people who were there who had worked in the company for a long time, who knew what the next step was. (Informant 8)

The POE website thus continued to consolidate knowledge that had previously resided only in the heads of experienced engineers.

Not everyone was an enthusiastic follower of POE, however. I deliberately sought informants who would provide variance in terms of their attitudes toward standardized work. Six of my informants recommended I interview and observe members of a particular engineering team that had the reputation of being POE detractors. Accordingly, I spent a full week with this team, interviewing all nine members and observing their work patterns. Three of the team's 
engineers expressed annoyance at the burden of documentation that POE required. (This issue was echoed by four EG-2 informants outside this team). In each case, however, the engineers continued to use the POE system. Their sentiments are captured in the following comment:

The paperwork and the documentation are just not a typical engineer's strength and/or interest. And so, that's been one of the biggest problems, is getting the collateral posted or referenced properly...documenting the fact that we're doing all the things we say we're doing. . . . I mean, again, it's not to badmouth the system, because its intent is noble, it's just the execution's tough. (Informant 20)

A second area of concern within this team was the feeling that POE had been 'overengineered': that the detailed, standardized work processes were geared toward developing new components, and were excessive for handling routine tasks. But even these critics complied with POE standards; their complaints did not occasion decoupling. As one engineer put it, he had not heard 'anyone complain overly... not to the extent of, “The system's flawed and what a waste of time” type of deal’ (Informant 33).

Perhaps the most striking evidence of how deeply the standards had become embedded in the engineers' practices came from a manager who had authorized his group to violate the standards in response to a crisis:

We had a program recently where we were asked to do everything in one-third the time that we normally do it, and we got pretty much the okay not to follow the process. All of my folks had tremendous anxiety about not following the process. They all felt it was going to take them longer actually not to follow a process. They needed to do the process anyway to make sure things were done right. So to say, 'Hey, don't take the time to do all the calculations. Just do the ones you think are important.' 'Well, the ones I think are important are the ones that I always do.' 'Well, just do half the things you think are so important.' 'Well, does that mean it only has to be half-right?' That's probably the best example I can give you of how people believe in this. (Informant 10a)

To summarize, although both EG-1 and EG-2 initiated and successfully executed ISO 9000 certification drives, the antecedents and effects of their efforts have little in common. Within EG-1, layers of failed top-down attempts at standardization have led to feelings of 
cynicism and fatigue among engineers, who express a distinct distaste for the hollow ceremony associated with ISO certification. In the case of EG-2, adoption of ISO 9000 was a business necessity and implemented as such, with minimal disruption to existing patterns of work. Both of these implementations were decoupled from core engineering processes. In EG-2, however, a robust standardization tool evolved from the bottom up and was tightly coupled to the engineers' daily work. It was almost universally followed, making EG-2's continued ISO certification a mere formality. Represented within the two cases, then, are three different paths to standardization. I now turn to a more general, theoretical formulation of these three paths and their relationship to decoupling.

\section{DISCUSSION}

This paper began with a puzzle: What factors explain how two engineering divisions within the same corporation achieved such divergent outcomes in the pursuit of standardization? The detailed presentation of these cases in the previous section now serves as the basis for a general model of how different types of social regulation - standards, directives, and norms - are implicated in the adoption and implementation of an external standard among knowledge workers. I first consider how the translation of a standard into a directive helps explain the oftnoted link between standardization and decoupling (Walgenbach 2001; Boiral 2003; Storz 2007). Furthermore, I articulate how the interaction between organizational directives and occupational norms may predict the type of decoupling that results: the cynical, corrosive version seen in EG1, or the more trusting and transparent variety seen in EG-2. Finally, the proposed model illuminates the processes that lead to tight coupling, an unexpected outcome in studies of standardization.

\section{The missing level of analysis}


Theories of administrative standardization have focused on actors at two levels of analysis. At the level of the institutional field are the standards developing organizations that promulgate rational myths in the form of general principles and techniques (Meyer and Rowan 1977; Beck and Walgenbach 2005; Boiral 2007). At the organizational level of analysis are the adopters of standards: organizations who seek the efficiency or legitimacy that the standard promises. Once adopted, the standard can be implemented substantively or symbolically, as captured in Brunsson and Jacobsson's (2000b) distinction between 'practicing standards' and 'standardizing practice.' Common to both types of implementation is the term practice, which necessarily involves groups of practitioners. It is at this level of analysis - the myriad technical and functional departments, work groups, and other subunits in complex organizations - that a standard's fortunes are ultimately determined. Thus, for a standard to be put into practice, it must cross two crucial social boundaries: between the institutional field and the organization, and subsequently between the organization and the affected technical or functional subunit, with its own occupational norms and subculture.

Studies of standardization have neglected the crucial role of technical experts on the receiving end of standards. Indeed, professional expertise and standardization typically are portrayed as co-constitutive: As groups of experts coalesce around shared knowledge and interests, they tend to codify their expertise and promulgate rules to govern its application and lay claim to occupational jurisdiction (Abbott 1988). Some of these rules take shape as professional norms, while others are instantiated in standards (Jacobsson 2000), leading Scott (2008) to christen professionals as 'lords of the (institutional) dance.' But when such standards are to be implemented by members of a profession that did not create them, an ironic inversion ensues: Professionals become the objects rather than the agents of standardization, expected to 
follow the steps without calling the tune. This role reversal engenders an inflection point in the standardization process. To the degree that abstract external standards are enforced by managerial mandate, they become decoupled from technical work. In contrast, if experts choreograph the dance, codifying their own tools and practices, the resulting standards reflect local realities and enable tight coupling between the technical core and an institutional exigency.

Figures 2a and 2b offer a schematic representation of the boundaries that an external standard must cross if it is to influence actual work practices. At each crossing, the standard is transformed into a different type of social regulation. Adoption transforms the standard into a directive. Implementing the directive further converts the standard into formal structure and acquits it with the trappings of bureaucracy: a departmental home, a budget, incentives for compliance, and a rational discourse justifying its adoption (Meyer and Rowan 1977; Zbaracki 1998). Crossing the organization-group boundary requires yet another transformation, as the standard-cum-directive must be assimilated into the norms and practices of the work group. The first transformation (from standard to directive) is readily accomplished; the nature of managerial work is to transform abstract goals into actionable programs. The second transformation (from directive to norm) is rarely seen. It faces the formidable obstacle noted above: the abstract standard, endowed with the managerial authority of a directive, must mesh with the occupational norms and situated, contextualized practices of those who actually perform the work (Barley and Kunda 2001).

Two of the defining characteristics of standards become problematic at the level of the work group. First, because standards are 'expert knowledge stored in the form of rules' that are ‘de-contextualized in space and time’ (Jacobsson 2000: 41), the organization’s own expert workers can easily construe the standards as irrelevant or intrusive. Witness the common reaction 
among EG-1's engineers that they were not 'knowledge robots.' Second, although standards are distinguished by their voluntary adoption, only senior executives exercise volition; the rest of the organization must comply. Indeed, for EG-1 engineers, failure to follow the organization's ISO 9000 program was an invitation to be ‘flogged’ by upper management. Such managerial control runs counter to the principle of professional autonomy enshrined in the knowledge-worker ethos (Bailyn 1985; Petroski 1992; Kunda 1992; Alvesson 2001).

\section{Diagnosing decoupling}

Both ISO 9000 implementations illustrate the failure of an external standard to be assimilated by a group of technical experts, although with markedly different effects on the experts themselves. EG-1's implementation featured a cadre of quality experts - separated administratively and occupationally from the engineers - who issued work instructions. Past history led the engineers to doubt the organization's commitment to quality; instead, the standardization project was interpreted as an attempt to exert managerial control. The cynical variant of decoupling that ensued has been observed in numerous other empirical studies. For example, Boiral's (2003) analysis of attitudes toward ISO 9000 among Canadian implementers identified a large group of 'dissident' workers who minimally (and cynically) complied with the quality management system; and Walgenbach (2001) found similar emotions among German ISO 9000 adopters. Common to these accounts is an element of hypocrisy: managers espoused substantive change but enacted only symbolic compliance (Brunsson 2000).

In contrast, EG-2 initially adopted the ISO 9000 standard as a commercial necessity. EG2's leaders were straightforward regarding the symbolic nature of compliance, and thus made no serious effort to change technical work arrangements. Decoupling ensued, but hypocrisy was muted. Similar candor characterized Boiral’s (2003: 726) 'ceremonial integrators;' in the words 
of one, 'ISO is mainly a marketing tool for us.' In her study of ISO 9000 implementations in Japan and Germany, Storz (2007: 236) found that 'almost all firms regard the standard as an empty shell’ yet considered decoupling 'not as a problem but a solution to a problem.' Hallett and Ventresca (2006: 221) also noted a harmless version of decoupling, termed 'mock bureaucracy,' that is, ‘a “loosely-coupled” system of indulgency (worker autonomy) dressed in ceremonial clothes of bureaucratic accountability.'

[ Figures 2a and 2b here ]

That these contrasting effects have been observed repeatedly suggests the existence of two different strains of decoupling: a malignant strain, corrosive to motivation and morale (Figure 2a); and a benign strain, characterized by transparency and accommodation (Figure 2b). This distinction between types of decoupling answers calls for more attention to the internal dynamics of decoupling (Boxenbaum and Jonsson 2008; Behnam and MacLean 2011), and prompts an additional question: Under what conditions do we see which type of decoupling? Obvious differences exist between EG-1 and EG-2. EG-1 has no direct external customers; EG-2 was pressed to adopt ISO 9000 by its external customers. EG-1's workforce consists of engineers brought together from different product divisions; EG-2’s engineers had worked together, under the same roof, for two decades. EG-1's engineering tasks were integrative and rife with interdependencies; EG-2 designed a modular component in relative isolation. It is tempting to invoke contingency theory and argue that the different modes of standardization primarily reflect differences in their environments.

Certainly, the type of decoupling that each group enacted may be associated with sociotechnical contingencies. For present purposes, however, it is sufficient to note that both groups initially converted an external administrative standard into an organizational directive, yielding 
decoupled implementations. EG-1 abandoned external ISO certification, but continued to pursue its own version of standardization in a haphazard, decoupled manner. EG-2 maintained its benign decoupling for approximately 10 years before creating a tightly-coupled 'Process of Engineering.' This latter development now requires explanation.

\section{The anomaly of tight coupling}

I return to the notion of the transformation of social regulation. When standards are 'homegrown,' the standards assimilate the group’s processes, rather than the group assimilating standard processes. Adoption - defined as ‘taking for one’s own use something originated by another' (Merriam-Webster 2011) - never occurs. Either the standard diffuses across groups via network channels, or it is transformed into a directive by an executive champion. If the internal standard is of sufficient rigor, external certification becomes a simple word game: 'Existing practice is continued but now described in accordance with the [external] standard' (Brunsson and Jacobsson 2000b: 128).

Figure 2c diagrams the ‘bottom-up’ process that produced POE. The project that grew into EG-2’s POE was initiated by an engineering team leader; his goals were to eliminate wasted effort and reconcile multiple tools being used to accomplish the same task within his team. As an example, this team leader recalled the confusion that resulted from different versions of a report called an 'application matrix':

Team leader: [The application matrix] is a deliverable that is always in front of us. We cover that all the time in this meeting; that's what this meeting is all about.

Interviewer: And that matrix existed before POE, or is that a new -

Team leader: Well, it existed in some way, shape or form. It’s just that we standardized it. Interviewer: So, now everybody uses this? 
Team leader: Yeah, I mean, so we were tired of seeing - this time it's PowerPoint, now it's Word, now it's green, it's blue, it's upside down - it's like, 'Hey, you're going to use this form!' (Informant 10a)

At the team leader’s insistence, the engineers designed their own standards based on intimate knowledge of the work itself. Their avowed goal was not to satisfy ISO requirements, nor even to follow an executive directive. Instead, they saw standardization as a way to make their work more efficient and meaningful by simplifying and clarifying the administrative apparatus surrounding their engineering tasks. The eventual result was a comprehensive set of protocols that met ISO 9000 requirements - and that became so much a part of the engineers' culture that, when given the option to abandon the standards, they chose to follow them anyway. Meeting ISO requirements may not have been an explicit design criterion among POE's architects, but it was certainly not accidental. Having been continuously ISO certified since 1997, EG-2 had developed compliance-related roles and routines that permeated the organization. In effect, ISO certification had become taken for granted, an institutionalized element of EG-2's activities. That POE would be ISO compliant was never in question, thus producing the anomaly of a technically-driven activity tightly coupled to an institutionallyderived demand.

\section{[ Figure 2c here ]}

Two additional factors are noteworthy in the evolution of tight coupling within EG-2. First, as predicted by the basic model of standardization advanced in this paper, POE encountered resistance as it was converted from a group-level protocol into a division-wide directive. Indeed, one observer was quite blunt in his description of the engineers' recalcitrance: 'They went kicking and screaming the whole way' (Informant 59). Such resistance, however, did not occasion decoupling. As recounted above, 11 of 43 EG-2 informants indicated that, 
eventually, POE’s practical advantages won them over. Because it had been created by engineers, for engineers, POE was able to overcome the 'Not-Invented-Here' dynamics that plagued EG-1's attempt at standard work. The following comment is representative:

A lot of what people said when we were doing this [implementing POE], is that, you know, you're taking the spirit out of it, the innovativeness. I can't be an engineer. I can't create anymore. But as you got into it, you could still do that, you'd loop through each of the elements and you still apply creativity, and it all worked out okay. (Informant 17)

Second, internal audits played a crucial role in embedding POE in daily practice. Existing research highlights the importance of external audits (e.g., Seidl 2007), but the POE case indicates that internal audits can offer similar enforcement. Missing from previous analyses, however, is the view provided here of an audit as a feedback loop, ensuring that the standard continuously reflects current practice.

The themes of enrollment and autonomy in the foregoing account resonate with prior research on participatory processes. Rombach (1993), for example, describes a successful homegrown government reform that flourished in the absence of top-down control. Similarly, Vallas (2003: 242) found that local autonomy and worker-level expertise figured prominently in the success of the NewTown paper mill's quality initiative: 'Because NewTown’s variant of [quality improvement] has not been tethered to corporate control, it has been able to adapt to local exigencies.' In contrast, comparable initiatives at three other mills failed, in part, due to conflict between corporate management's 'logic of standardization' and the 'logic of participation' necessary for worker-driven improvement efforts (Vallas 2003: 238, italics in original). Commenting on the spread of evidence-based standards in medicine, Thévenot (2009: 794) observed that 'participation in the process of form-giving can be a means to prevent a standard from becoming external to one’s own concerns.' 
The present study extends prior findings by relating the construct of participation to the broader concept of social regulation and three of its manifestations: standards, directives, and norms. Participation allows technical experts to fuse standards and norms, and the resulting fusion is better equipped to overcome resistance when transformed into a directive and implemented more broadly in the organization.

\section{CONCLUSION}

At all levels of relations, from interpersonal to international, rules permeate social life. They govern and coordinate, undergird sensemaking, and bound action. Of the three categories of rules theorized by Brunsson and Jacobsson (2000a), norms are the least obtrusive and the most powerful. Directives are the least adaptable, requiring an authority structure in which to operate. Standards are more subtle than directives, able to insinuate themselves into an actor's voluntary exercise of agency and catalyze the creation of directives or the evolution of norms.

Brunsson and Jacobsson (2000a:13) intimate a degree of interconnectedness among types of social regulation when they state, 'In reality, it is not particularly easy, and not always necessary, to distinguish between our three types of rules. The same content can appear in norms, directives, and standards.' This paper advances a more definitive set of propositions: In the process of adoption, external standards become directives. When such directives threaten the occupational norms and practices of those expected to implement them, a malignant form of decoupled compliance is observed. If instead the directives accommodate the norms and practices of the targeted occupational group, a benign form of decoupled compliance develops. If, however, the standards originate within the group and incorporate its norms and practices, then the resulting directive will encounter less resistance. Tightly-coupled compliance with the external standard is thus rendered possible. 
This view of standards raises questions about the unintended consequences of standardization. Quite possibly the most salient feature of standards is their ability to engender directives in organizations. Indeed, the adoption of a standard is actually a transmutation: The rationalized myth is clothed in structural form and adorned with incentives and sanctions. Such structures may be difficult to dismantle. For example, EG-1's dalliance with ISO 9000 has resulted in a staff organization that is not only decoupled, but vestigial. Assuming EG-1 is not an isolated case, one wonders how much organizational clutter gets left in the wake of attempted standardization. At what point might an organization crumble under the accumulated detritus of past standards-inspired directives? Does malignant decoupling undermine organizational effectiveness to a greater degree than benign decoupling? Such performance-related questions merit further research.

In addition, future inquiry might examine standardization through the lens of occupational identities. The data in this study are laden with identity implications. EG-1's engineers, for example, resisted the standard largely because it challenged their self-concept. If individuals conform to norms in order to validate a particular identity (Cancian 1975), then the adoption of an external norm may be perceived as 'identity-discrepant' and thus resisted (Rao et al. 2003). To the degree that an external standard is presented in what might be termed an 'identity-concordant' manner, then the dynamics outlined in this paper may work in favor rather than against its adoption.

Perhaps a more penetrating question involves organizational alternatives to adopting a standard. If adoption strips a standard of its unique voluntariness, how else might an organization engage a standard? Detailed examination of cases in which an executive endorses or recommends (rather than adopts) a standard - or more to the point, charters a group of internal 
experts to standardize their own work processes in a manner consistent with external certification demands - may shed additional light on the organizational conditions favorable to tight coupling between external standards and local occupational norms. 


\section{REFERENCES}

Abbott, Andrew

1988 The system of profession: an essay on the division of expert labor. University of Chicago Press.

Abernethy, Margaret A. and Johannes U. Stoelwinder

1995 'The role of professional control in the management of complex organizations'. Accounting, Organizations, and Society 20 (1): 1-17.

Ahrne, Göran, Nils Brunsson and Kristina Tamm Hallström 2007 'Organizing organizations'. Organization 14(5): 619-624.

Alvesson, Mats

2001 'Knowledge work: Ambiguity, image and identity’. Human Relations 54:863 -886.

Bailyn, Lotte

1985 'Autonomy in the R\&D Lab’. Human Resource Management 24 (2): 129 -146.

Barley, Stephen R.

1986 'Technology as an occasion for structuring: evidence from observations of CT scanners and the social order of radiology departments'. Administrative Science Quarterly 31: 78108.

Barley, Stephen R., and Gideon Kunda

2001 'Bringing work back in'. Organization Science 12: 76-95.

Beck, Nikolaus and Peter Walgenbach

2005 'Technical efficiency or adaptation to institutionalized expectations? The adoption of ISO 9000 standards in the German mechanical engineering industry’. Organization Studies 26:841-866.

Behnam, Michael and Tammy L. MacLean.

2011 'Where is the Accountability in International Accountability Standards? A Decoupling Perspective.’ Business Ethics Quarterly, 21(1):45-72.

Boiral, Olivier

2003 'ISO 9000: Outside the iron cage.’ Organization Science 14(6): 720-737.

Boiral, Olivier

2007 'Corporate greening through ISO 14001: A rational myth?' Organization Science 18(1): 127-146. 
Boxenbaum, Eva, and Stefan Jonsson

2008 'Isomorphism, diffusion and decoupling'. The Sage handbook of organizational institutionalism. Royston Greenwood, Christine Oliver, Kerstin Sahlin-Andersson, and Roy Suddaby (eds), Sage Publications.

Bromley, Patricia, Hokyu Hwang, and Walter W. Powell

2011 'Institutional junctures: Key points of divergence in the process of institutionalization'. Stanford University working paper.

Brunsson, Nils

2000 'Standardization and fashion trends'. A world of standards. Nils Brunsson and Bengt Jacobsson (eds), 151-168. Oxford Univ. Press.

Brunsson, Nils, and Bengt Jacobsson

2000a 'The contemporary expansion of standardization'. A world of standards. Nils Brunsson and Bengt Jacobsson (eds), 1-17. Oxford Univ. Press.

Brunsson, Nils and Bengt Jacobsson

2000b 'Following standards'. A world of standards. Nils Brunsson and Bengt Jacobsson (eds), 127-137. Oxford Univ. Press.

Brunsson, Nils, and Johan P. Olsen

1993 The reforming organization. New York: Routledge.

Brunsson, Nils and Kerstin Sahlin-Andersson

2000 'Constructing organizations: The example of public sector reform'. Organization Studies 21(4): 721-746.

Cancian, Francesca M

1975 What are norms?: A study of beliefs and action in a Maya community. Cambridge University Press.

Czarniawksa, Barbara and Guje Sevón (eds)

1996 Translating organizational change. Berlin: de Gruyter.

Djelic, Marie-Laure, and Sigrid Quack

2008 'Institutions and transnationalization'. The Sage handbook of organizational institutionalism. Royston Greenwood, Christine Oliver, Kerstin Sahlin-Andersson, and Roy Suddaby (eds), 299-323. Sage Publications.

Djelic, Marie-Laure, and Kerstin Sahlin-Andersson

2006 Transnational governance: Institutional dynamics of regulation. Cambridge University Press.

Eisenhardt, Kathleen M 
1989 'Building theories from case study research’. Academy of Management Review 14: 488511.

Eisenhardt, Kathleen M. and Melissa E. Graebner

2007 'Theory building from cases: Opportunities and challenges'. Academy of Management Journal 50(1): 25-32.

Espeland, Wendy N

1998 The struggle for water. University of Chicago Press.

Feldman, Martha S. and Brian T. Pentland.

2003 'Reconceptualizing organizational routines as a source of flexibility and change'. Administrative Science Quarterly 48: 94-118.

Fiss, Peer C. and Edward Zajac

2006 'The symbolic management of strategic change: Sensegiving via framing and decoupling'. Academy of Management Journal 49(6): 1173-1193.

Furusten, Staffan

2000. 'The knowledge base of standards'. A world of standards. Nils Brunsson and Bengt Jacobsson (eds), 71-84. Oxford Univ. Press.

Hallett, Timothy

2010 'The myth incarnate: Recoupling processes, turmoil, and inhabited institutions in an urban elementary school’. American Sociological Review.

Hallett, Tim and Marc J. Ventresca

2006 'Inhabited institutions: Social interactions and organizational forms in Gouldner's Patterns of industrial bureaucracy.' Theory and Society 35: 213-236.

Higgins, Vaughan and Wendy Larner (eds)

2010 Calculating the social: Standards and the reconfiguration of governing. Hampshire, UK: Palgrave MacMillan

Hülsse, Rainer, and Dieter Kerwer

2007 'Global standards in action: Insights from anti-money laundering regulation'. Organization 14: 625 -642.

Jacobsson, Bengt

2000 'Standardization and expert knowledge'. A World of Standards. Nils Brunsson and Bengt Jacobsson (eds), 40-49. Oxford Univ. Press.

Kunda, Gideon

1992 Engineering culture: culture and control in a high-tech organization. Philadelphia: Temple Univ. Press. 
Lampland, Martha and Susan Leigh Star (eds)

2009 Standards and their stories: How quantifying, classifying, and formalizing practices shape everyday life. Ithaca: Cornell Univ. Press.

Lawrence, Paul R. and Jay W. Lorsch

1969 Organization and environment: Managing differentiation and integration. RD Irwin.

MacLean, Tammy L. and Michael Behnam

2010 'The dangers of decoupling: The relationship between compliance programs, legitimacy perceptions, and institutionalized misconduct’. Academy of Management Journal 53(6): 1499-1520.

Mattli, Walter, and Tim Büthe

2003 'Setting international standards: Technological rationality or primacy of power?' World Politics 56(1): 1-42.

Merriam-Webster

2011 Definition of ‘adoption’ found online at http://www.merriamwebster.com/thesaurus/adopt. Downloaded 03 Feb 2011.

Meyer, John W., and Brian Rowan.

1977 'Institutionalized organizations: Formal structure as myth and ceremony'. American Journal of Sociology 83(2): 340-363.

Meyer, John, John Boli, George M. Thomas, and Francisco O. Ramirez

1997 'World society and the nation-state'. American Journal of Sociology 103(1): 144-181.

Miles, Matthew B. and A. Michael Huberman

1984 Qualitative data analysis: A sourcebook of new methods. Sage Publications.

Oliver, Christine

1991 'Strategic responses to institutional processes'. Academy of Management Review 16: 145179.

Pache, Anne-Claire and Filipe Santos

2010 'When worlds collide: The internal dynamics of organizational responses to conflicting institutional demands'. Academy of Management Review 35: 455-476.

Petroski, Henry

1992 To engineer is human: The role of failure in successful design. NY: Vintage.

Rao, Hayagreeva, Philippe Monin, and Rodolphe Durand

2003 'Institutional change in Toque Ville: Nouvelle cuisine as an identity movement in French gastronomy’. American Journal of Sociology 108: 795-843. 
Rombach, Bjorn

1993 'Success at the expense of control'. The Reforming Organization. Nils Brunsson and Johan P. Olsen (eds), 143-162. NY: Routledge.

Scott, W. Richard

2008 'Lords of the dance: Professionals as institutional agents'. Organization Studies 29(2): 219-238.

Scott, W. Richard and Gerald F. Davis

2007 Organizations and organizing: rational, natural, and open systems perspectives. Pearson Prentice Hall.

Scott, W. Richard and John W. Meyer

1991 'The organization of societal sectors: Propositions and early evidence'. The new institutionalism in organizational analysis. Walter W. Powell and Paul J. DiMaggio (eds), Univ. of Chicago Press: 108-140.

Seidl, David

2007 'Standard setting and following in corporate governance: An observation-theoretical study of the effectiveness of governance codes’. Organization 14: 705 - 728.

Stevens, John M., H. Kevin Steensma, David A. Harrison, and Philip L. Cochran

2005 'Symbolic or substantive document? The influence of ethics codes on financial executives’ decisions’. Strategic Management Journal 26 (2): 181-195.

Storz, Cornelia

2007 'Compliance with international standards: The EDIFACT and ISO 9000 standards in Japan’. Social Science Japan Journal 10(2): 217-241.

Strauss, Anselm L. and Juliet Corbin

1990 Basics of qualitative research. Sage Publications.

Sauder, Michael and Wendy N. Espeland

2009 'The discipline of rankings: Tight coupling and organizational change'. American Sociological Review 74: 63-82.

Tamm Hallström, Kristina

2000 'Organizing the process of standardization'. A World of Standards. Nils Brunsson and Bengt Jacobsson (eds), 85-99. Oxford Univ. Press.

Tamm Hallström, Kristina

2004 Organizing international standardization: ISO and the IASC in quest for authority. Northampton, MA: Edward Elgar.

Thévenot, Laurent 
2009 'Governing life by standards: A view from engagements'. Social Studies of Science 39(5): 793-813.

Timmermans, Stefan and Steven Epstein

2010 'A world of standards but not a standard world: Toward a sociology of standards and standardization’. Annual Review of Sociology 36: 69-89.

Vallas, Steven P

2003 'Why teamwork fails: Obstacles to workplace change in four manufacturing plants'. American Sociological Review 68: 223-250.

Walgenbach, Peter

2001 'The production of distrust by means of producing trust'. Organization Studies 22(4): 693 - 714.

Walgenbach, Peter

2007 'Façade and means of control: The use of ISO 9000 standards'. Quality Management in Food Chains. L. Theuvsen, A. Spiller, M. Peupert, and G. Jahn (eds), Wageningen: Wageningen Academic Publishers, 29-43.

Westphal, James D., Ranjay Gulati, and Stephen M. Shortell

1997 'Customization or conformity? An institutional and network perspective on the content and consequences of TQM adoption’. Administrative Science Quarterly 42 (2): 366-394.

Westphal, James D. and Edward J. Zajac

2001 'Decoupling policy from practice: The case of stock repurchase programs'. Administrative Science Quarterly 46: 202-228.

Zbaracki, Mark

1998 'The rhetoric and reality of Total Quality Management'. Administrative Science Quarterly 43: 602-636. 


\section{LIST OF TABLES}

Table 1:

Comparing Different Forms of Social Regulation

\begin{tabular}{|c|c|c|c|}
\hline & Norms & Directives & Standards \\
\hline Voluntarily adopted? & Yes & No & Yes \\
\hline Explicitly stated? & No & Yes & Yes \\
\hline Indentifiable author? & No & Yes & Yes \\
\hline
\end{tabular}

Source: adapted from Brunsson and Jacobsson 2000a 
Table 2:

Summary of Engineering Group 1 and Engineering Group 2 Informants

\begin{tabular}{|l|c|c|c|}
\hline & EG-1 & EG-2 & TOTAL \\
\hline Executive & 3 & 5 & 8 \\
\hline Manager & 6 & 6 & 12 \\
\hline Engineer & 9 & 25 & 34 \\
\hline Support Staff & 2 & 6 & 8 \\
\hline External & 0 & 1 & 1 \\
\hline Total & 20 & 43 & 63 \\
\hline
\end{tabular}


Table 3:

The Succession of Standardization Initiatives in EG-1

\begin{tabular}{|c|c|}
\hline INITIATIVE & DESCRIPTION \\
\hline $\begin{array}{l}\text { Synchronous workshops } \\
\text { (1994) }\end{array}$ & $\begin{array}{l}\text { Following the lead of the manufacturing organization, EG-1 attempts to } \\
\text { synchronize its product development processes to enable parallel engineering. }\end{array}$ \\
\hline Engineering Factory (1995) & $\begin{array}{l}\text { An attempt to re-energize the manufacturing-inspired synchronization effort. This is } \\
\text { the first time engineering is formally referred to as a 'factory.' }\end{array}$ \\
\hline $\begin{array}{l}\text { 'Lean Engineering Factory’ } \\
\text { Workshops (1996) }\end{array}$ & $\begin{array}{l}\text { Further entrenchment of the 'engineering factory' concept. The initiative is } \\
\text { workshop based; serious process redesigns are intended to follow. }\end{array}$ \\
\hline 'Lean Acceleration’ (1997) & $\begin{array}{l}\text { First effort to identify and implement common product development processes } \\
\text { across all engineering groups. The groups remain structurally separated, however, } \\
\text { and continue with separate identities and engineering approaches. }\end{array}$ \\
\hline $\begin{array}{l}\text { Product Development } \\
\text { Process (PDP) (1998) }\end{array}$ & $\begin{array}{l}\text { The PDP - a master project-schedule-coordinating mechanism - is designed and } \\
\text { launched. This is the first time 'standard work' terminology is used in engineering. }\end{array}$ \\
\hline $\begin{array}{l}\text { Constraints Management } \\
\text { Workshops (1999) }\end{array}$ & $\begin{array}{l}\text { Workshops and consulting based on the ideas of Eliyahu Goldratt (Theory of } \\
\text { Constraints) sweep through EG-1. The goal is to optimize the performance of the } \\
\text { engineering factory. }\end{array}$ \\
\hline $\begin{array}{l}\text { 'FastChange' Workshops } \\
\text { (2000) }\end{array}$ & $\begin{array}{l}\text { 'FastChange,' a different method for holding continuous improvement meetings, is } \\
\text { taught within the product development organization (including EG-1). }\end{array}$ \\
\hline Work Instructions (2001) & $\begin{array}{l}\text { For the first time, specific 'how to do your job' instructions are created by a central } \\
\text { 'process expert' group and introduced to EG-1 engineers. The principal objective is } \\
\text { to prepare for ISO } 9000 \text { registration. }\end{array}$ \\
\hline $\begin{array}{l}\text { ISO } 9000 \text { Registration } \\
(2002)\end{array}$ & External auditors grant EG-1 the ISO seal of approval. \\
\hline $\begin{array}{l}\text { ISO Registration allowed to } \\
\text { lapse (2004) }\end{array}$ & $\begin{array}{l}\text { VP of Engineering announces that EG-1 will no longer pursue external audits of its } \\
\text { quality processes, but that engineers should continue to follow the guidelines. }\end{array}$ \\
\hline
\end{tabular}


Table 4:

The Succession of Standardization Initiatives in EG-2

\begin{tabular}{|c|c|}
\hline INITIATIVE & DESCRIPTION \\
\hline $\begin{array}{l}\text { ISO 9000 Preparations } \\
\text { (1995) }\end{array}$ & $\begin{array}{l}\text { At the request of external customers, EG-2 begins preparations for ISO } 9000 \\
\text { certification. Effort is designed to disrupt engineering work as little as possible. }\end{array}$ \\
\hline $\begin{array}{l}\text { ISO } 9000 \text { Registration } \\
(1997)\end{array}$ & $\begin{array}{l}\text { External auditors grant EG-2 the ISO seal of approval. Registration has never been } \\
\text { allowed to lapse. }\end{array}$ \\
\hline $\begin{array}{l}\text { 'Engineering Standard } \\
\text { Work' Training Program } \\
\text { (2001) }\end{array}$ & $\begin{array}{l}\text { EG-2 taskforce develops a one-day workshop to help 'all people in the organization } \\
\text { who produce similar deliverables for product program execution do it the same way } \\
\text { every time' (AIM Training Manual, p.1-2). Attendance is mandatory for engineering } \\
\text { team leaders and above, and optional for engineers. }\end{array}$ \\
\hline $\begin{array}{l}\text { New Product Development } \\
\text { Team Creates Rigorous } \\
\text { Work Standards (2004) }\end{array}$ & $\begin{array}{l}\text { To eliminate duplication and confusion, engineering team leader takes his } \\
\text { engineers off the job for a week to create a structured sequence of input } \\
\text { requirements, output requirements, and document formats for all engineering } \\
\text { tasks. }\end{array}$ \\
\hline $\begin{array}{l}\text { New Executive Joins EG-2 } \\
(2004)\end{array}$ & $\begin{array}{l}\text { Executive supports the extension of the New Product Development Team's work to } \\
\text { all of EG-2. The resulting set of work standards is labeled 'Process of Engineering' } \\
\text { (POE). }\end{array}$ \\
\hline $\begin{array}{l}\text { Process of Engineering } \\
\text { (POE) Rolled Out in EG-2 } \\
\text { (2005) }\end{array}$ & $\begin{array}{l}\text { POE becomes a web-based tool launched that brings all work standards and } \\
\text { supporting documentation into a single virtual location. }\end{array}$ \\
\hline $\begin{array}{l}\text { Internal Audits of POE } \\
\text { Compliance (2006) }\end{array}$ & $\begin{array}{l}\text { Monthly audits ensure engineers are using POE tools and uploading } \\
\text { documentation to the POE website. Auditors also collect improvement suggestions } \\
\text { from engineers and feed these back to a 'change review board' for inclusion in } \\
\text { POE. }\end{array}$ \\
\hline $\begin{array}{l}\text { POE Spreads to EG-2 } \\
\text { Counterparts in Asia and } \\
\text { Europe (2008) }\end{array}$ & POE becomes a global system for ensuring standardized work. \\
\hline
\end{tabular}




\section{LIST OF FIGURES}

Figure 1:

'Process of Engineering' (POE) Website:

Total number of distinct users per month

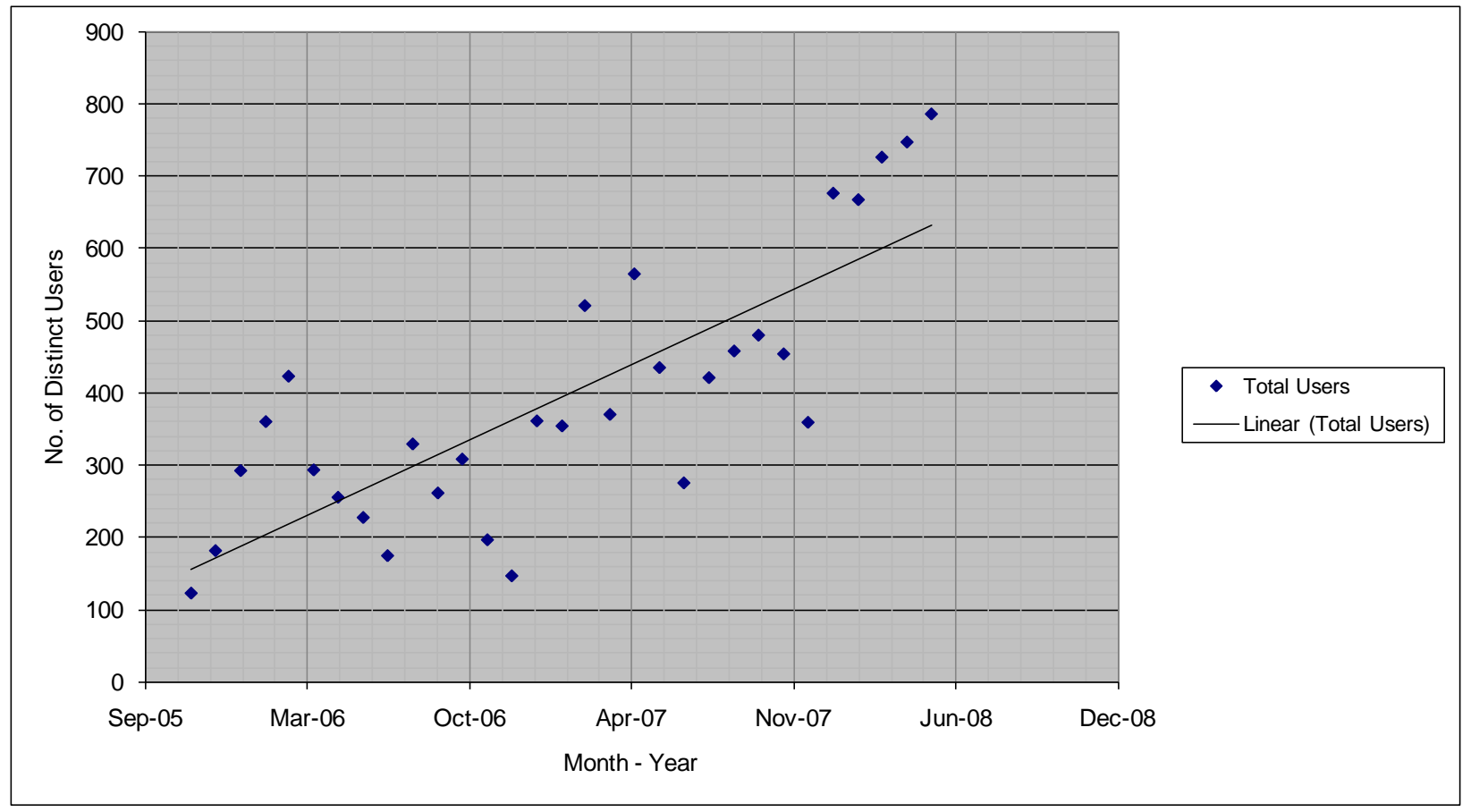

Source: AIM internal documentation 


\section{Figure 2a:}

The process of malignant decoupling in response to adoption of an external standard

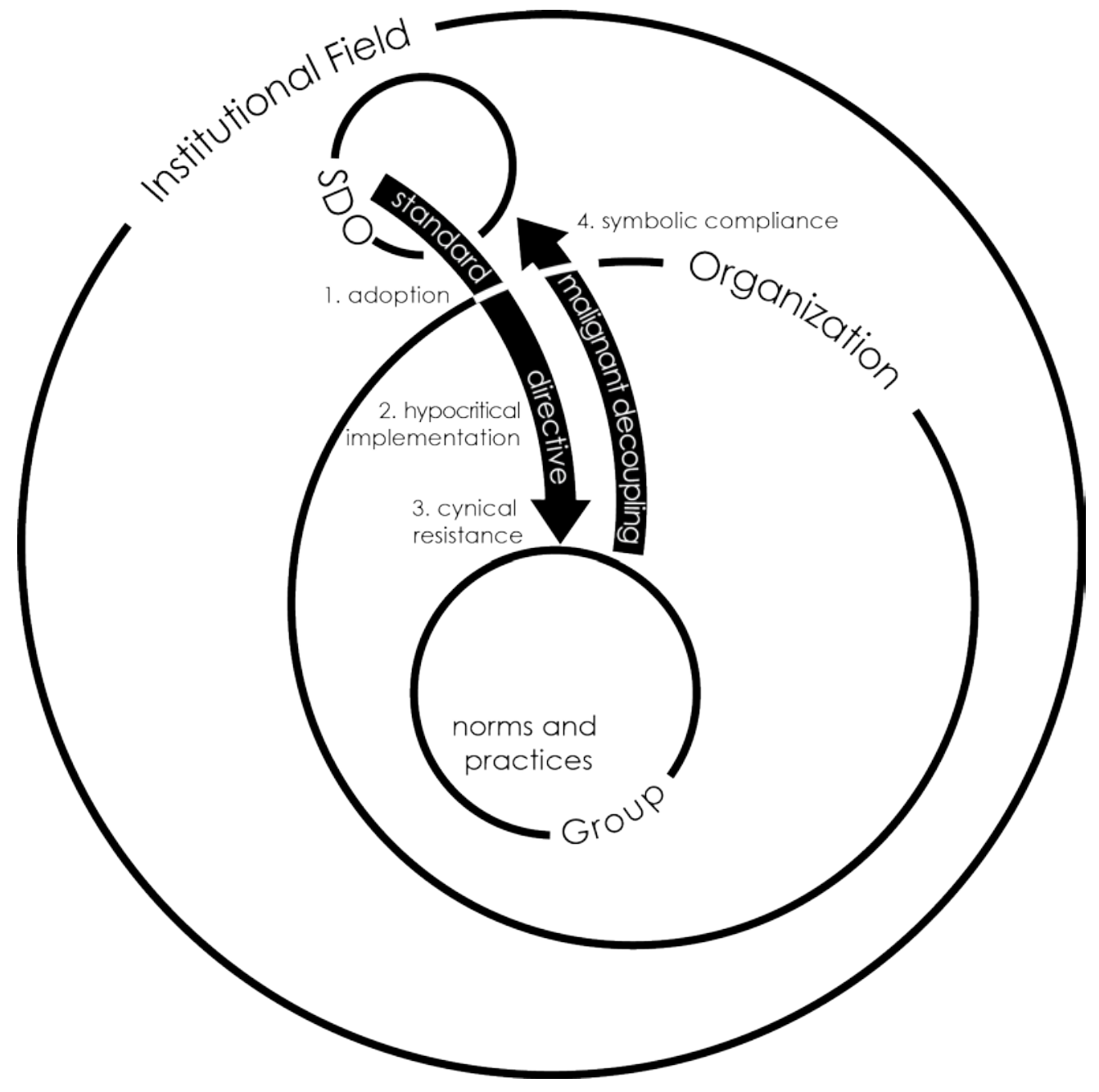

$S D O=$ Standards developing organization 
Figure 2b:

The process of benign decoupling

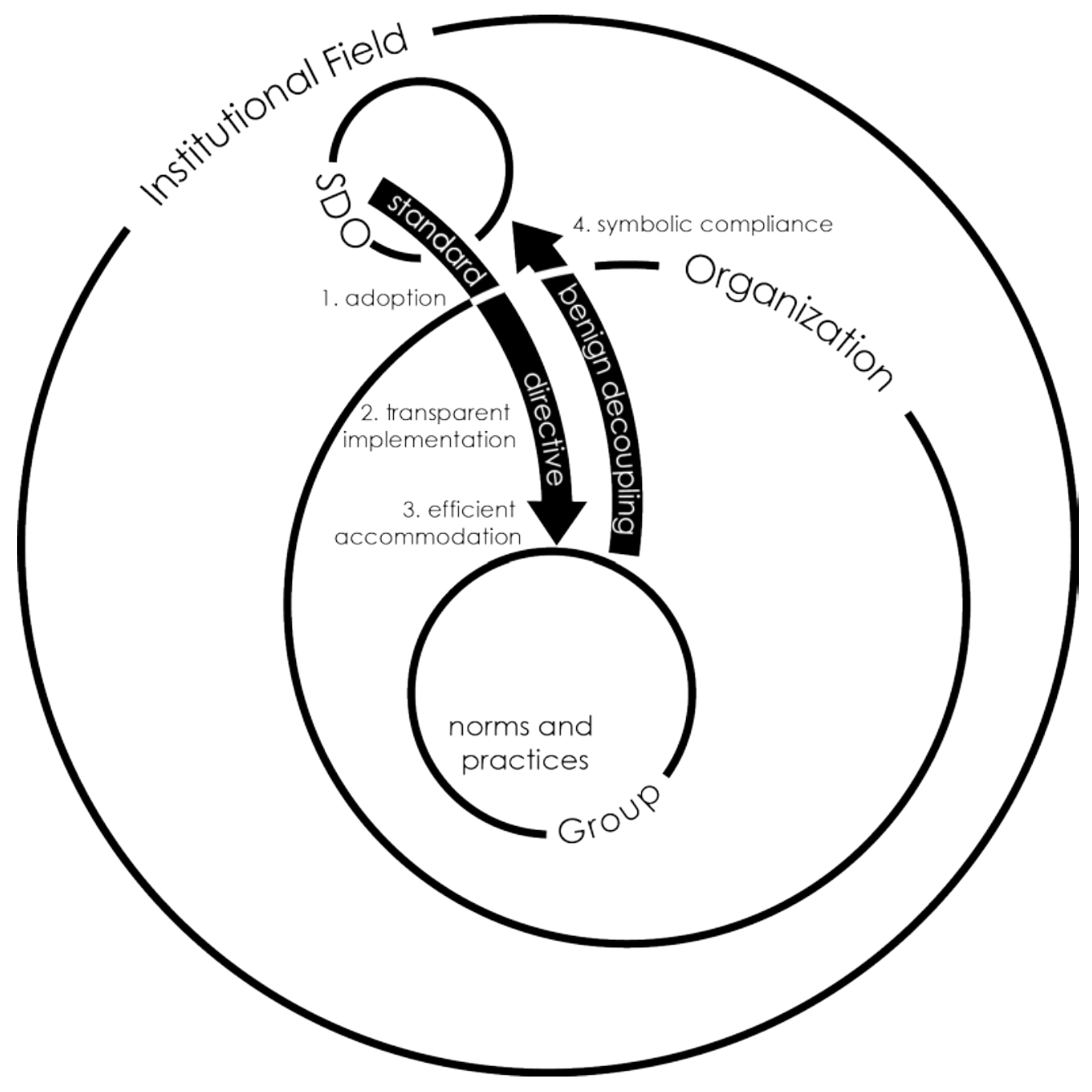


Figure 2c:

A process of origination and diffusion that leads to tight coupling

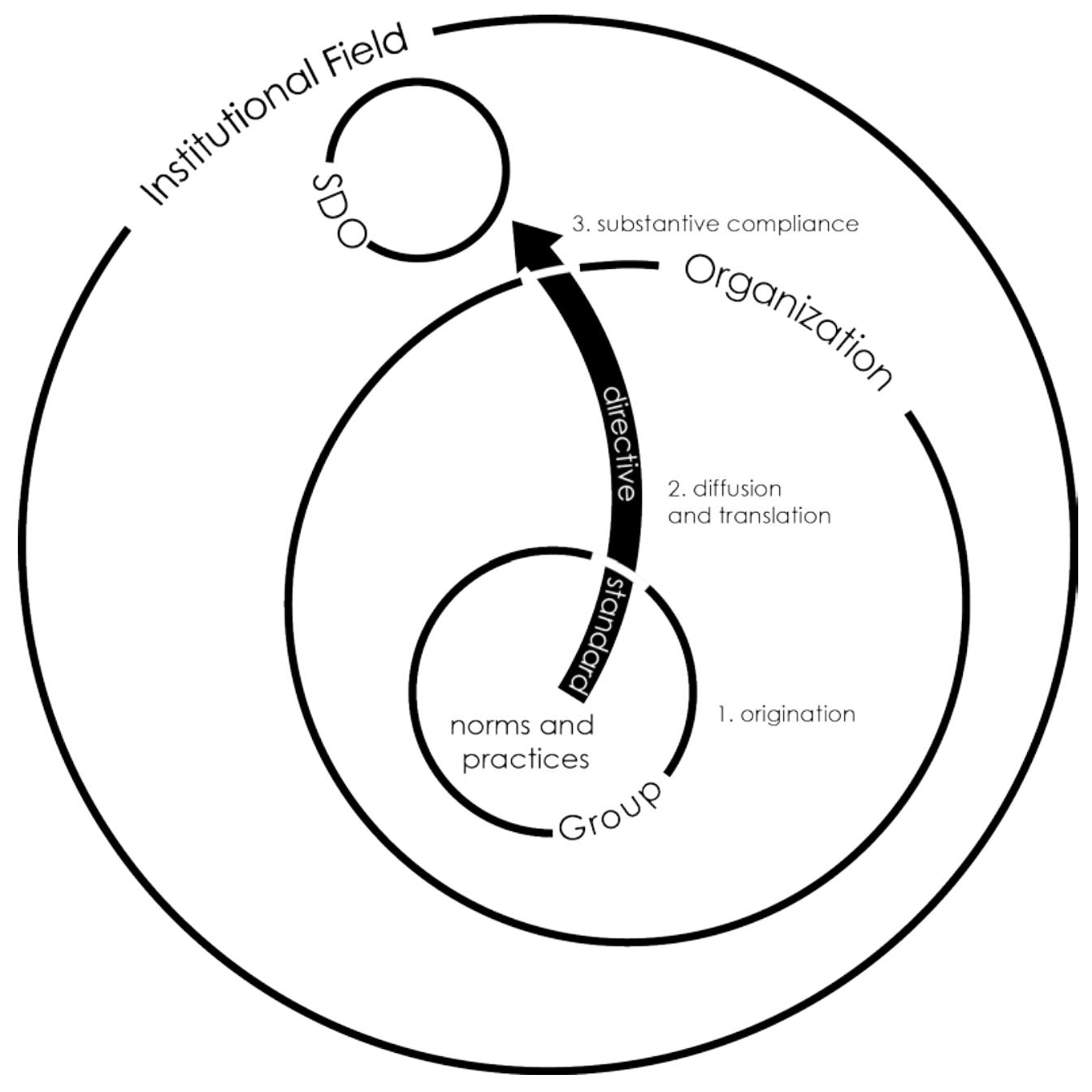

